\title{
SPATIAL DYNAMICS OF VERTICAL AND HORIZONTAL INTERGOVERNMENTAL COLLABORATION
}

\author{
ELISABETH R. GERBER \\ University of Michigan \\ CAROLYN G. LOH \\ Wayne State University
}

\begin{abstract}
Although researchers have made progress in understanding motivations behind local government collaboration, there is little research that explores the spatial dynamics of such interactions. Does the idea of collaboration travel horizontally, passed from neighbor to neighbor, or is vertical leadership from state, county, or regional actors more important in influencing local governments' decisions to share resources and functions? What factors influence local governments' choices to collaborate with their neighbors versus a regional entity, county, or state government? In this article, we investigate the importance of vertical and horizontal influences when local governments decide to collaborate around land use planning. Using data from a survey of Michigan local government officials, we take a spatial statistical approach to answering this question. We find widespread evidence of collaboration at multiple scales, and observe patterns of both horizontal and vertical influence. We also find that contextual factors help to explain these patterns of collaboration.
\end{abstract}

En thusiasm for regional land use planning has evolved from the "early days" of the 1990s, when advocates recommended new regional governments with broad powers, to a more recent emphasis on voluntary interlocal collaborative efforts. In the current era of fiscal austerity, such collaborative efforts are also gaining support from politicians interested in eliminating duplication of services between small jurisdictions (Snyder, 2011). However, we still do not know much about what motivates communities to collaborate (Carr, Gerber, \& Lupher, 2009), nor do we know if the theoretical shift in emphasis from regional to interlocal planning has been accompanied by a similar enthusiasm for interlocal land use planning agreements in practice. Furthermore, collaboration is inherently spatial. To collaborate, a local government needs partners-neighboring jurisdictions, counties, or regional organizations-with which to collaborate. A local government may also need other resources provided by neighboring jurisdictions or organizations to facilitate collaboration, including information, leadership, capacity, experience, and evidence of best practices. In each case, proximity matters: the availability of partners, information and resources will depend to a large extent on geographic location (Post, 2002). To our knowledge, the planning and urban policy literatures have not yet empirically tested the potentially important spatial component of partnership between governments. We also do not yet understand what factors influence whether governments collaborate horizontally, vertically, or both.

This study seeks to understand in what ways local governments are actually involved in collaboration - vertically (with regional and/or county partners), horizontally (with other local governments), or with some combination of both-and how spatial effects at various geographic scales

Direct correspondence to: Elisabeth R. Gerber, Ford School of Public Policy, University of Michigan, 735 South State Street, Ann Arbor, MI 48109.E-mail: ergerber@umich.edu.

JOURNAL OF URBAN AFFAIRS, Volume 37, Number 3, pages 270-288.

Copyright (C) 2014 Urban Affairs Association

All rights of reproduction in any form reserved.

ISSN: 0735-2166.

DOI: 10.1111/juaf.12139 
shape that collaboration. Specifically, we investigate three important questions about intergovernmental collaboration around land use. First, to what extent are horizontal and vertical collaboration complements versus substitutes? In other words, are communities who collaborate with their peers more or less likely to collaborate with regional organizations, and vice versa? Second, to what extent does the spatial environment influence the way governments think about collaboration? Here, we explore whether it matters "what the neighbors are up to." Does an environment of collaboration lead a community to collaborate, or are there other, non-spatial factors that matter more? And finally, to what extent is the answer to question two a matter of motivation versus opportunity? In other words, if the data demonstrate spatial effects, are these effects the result of practical considerations, in which a jurisdiction seeks out partnerships to solve specific problems, or are they the result of cultural factors, either in that collaboration has become a standard regional approach to resolving issues or that entrepreneurial communities or agencies are creating a deliberate network of collaborations?

We employ two statistical approaches that prove to be useful tools for analyzing interlocal and regional patterns of collaboration. Using data from a recent survey of Michigan local government officials, the first approach employs multivariate regression analysis in which characteristics of a local government and its spatial context are explanatory variables in a regression analysis of general collaborative outcomes. The second approach is a hot spot analysis in ArcGIS that tests for the existence of clusters of high and low levels of collaboration around land use at different geographic scales. We demonstrate collaborative influences at three scales: interlocal, county, and regional. Our results indicate that while interlocal collaboration around land use planning is very much alive, largescale countywide and regional planning remain frequent forms of collaboration as well. We find that both internal and external factors shape a local government's decisions to collaborate horizontally or vertically, but that these factors have different effects on horizontal and vertical collaboration decisions, indicating that jurisdictions face different motivations to engage in different types of collaboration.

In the following section, we review the literature on regionalism and horizontal and vertical collaboration, with a particular emphasis on collaborative land use planning, and present our hypotheses. We then describe our data and methodology in detail, explaining how measures of spatial context and hot spot analyses can reveal spatial patterns that are otherwise unobserved. We then discuss our statistical results and present conclusions about how these findings and techniques may apply to future research.

\section{INTERGOVERNMENTAL COLLABORATION: HORIZONTAL AND VERTICAL}

Several recent studies have attempted to understand both what motivates local intergovernmental collaboration and what factors predict its success, with mixed results (e.g., Carr et al., 2009). Making the issue more complicated, motivations to collaborate may be different for "systems maintenance" functions, such as sewer and water and public safety, than for "lifestyle" functions, such as land use planning and social services (Gainsborough, 2002; Howell-Moroney, 2008; Williams, 1967). There is especially uncertainty in the literature around the role of fiscal capacity (Leroux \& Carr, 2007), although our own recent research suggests that fiscal pressures play a role in support for collaboration even on lifestyle functions like planning, where their influence was expected to be minimal (Gerber \& Loh, 2011). Furthermore, given the fragmented nature of the U.S. political system, it is unclear how the chain of influence flows between governments-horizontally or vertically-regardless of whether governments decide to work together at either an interlocal or a regional scale (Carr et al., 2009).

\section{Horizontal Collaboration}

Horizontal collaboration is defined as "joint activities involving two or more governmental units at the same level of government" (Carr et al., 2009, p. 208). There is some evidence that spatial considerations affect the likelihood of horizontal collaboration. Post (2002) finds that increased geographic 
density of governments (essentially, increased fragmentation), is associated with higher levels of collaboration, though her measure includes counties, cities, towns, and townships, making it impossible to distinguish between horizontal and vertical collaboration. Carr et al. (2009), however, find the opposite: increased local government fragmentation is associated with a decrease in collaboration both horizontally and vertically.

Although we typically think of these horizontal relationships as involving geographically proximate units collaborating around processes or service delivery (Leroux \& Carr, 2007), cities that are leaders on a particular issue, such as climate change policy, may collaborate with other high capacity cities on a national or even global level, forming "networks of pioneers for pioneers" (Kern \& Alber, 2009, p. 1).

Numerous studies have found that local government leadership is critical in decisions to collaborate around services (Post, 2004; Zeemering, 2009). Frederickson's theory of administrative conjunction posits local administrators as key actors in the "horizontal formal and informal" connections and relationships that lead to or preclude collaboration (Frederickson, 1999, p. 708). Collaboration depends in part on how interconnected administrators and other local government officials are, and how well they know and trust each other (Feiock, 2007; Gerber, 2005; Thurmaier, 2006). Regional norms around collaboration may affect local support for regional efforts (Olberding, 2002) and may in fact help predict the frequency and success of horizontal collaborative agreements (Visser, 2002). Proponents of voluntary horizontal collaboration to achieve regional goals call this approach "governance without government" (Savitch \& Vogel, 2000, p. 164).

Individual community characteristics may also help explain whether governments decide to collaborate with neighbors. For example, population characteristics such as income, education, and partisanship/ideology may affect residents' preferences for local government policies and practices (Gainsborough, 2002; Mohamed, 2008). Communities with lower property values and tax bases may consider the potential cost savings from collaboration to be of higher value than do wealthier communities. On the other hand, local governments may avoid partnering with neighboring communities seen as fiscally weak, not wanting to tie their fortunes to a bad risk (Carr et al., 2009).

\section{Vertical Collaboration}

In vertical collaboration, actors within a hierarchy of governments form partnerships in various ways. Higher levels of government, such as state, county, or regional governments, may influence local actions through enabling (creating guidelines and providing information), provision (providing services for local governments to advance a particular goal), and actual command-and-control authority (Kern \& Alber, 2009), although the first two (voluntary) collaborative relationships are much more common in the United States. ${ }^{1}$ Counties, in particular, have a built-in role in coordinating functions among local governments, as well as directly providing services, so it may make sense to "[extend] the theory of administrative conjunction to county government" (Zeemering, 2009, p. 169). ${ }^{2}$

Vertical collaboration in the area of land use planning can take the form of city-county (or township-county) partnerships in which the county provides planning services for the local jurisdiction; county-wide collaboration in which the county takes over primary planning functions for its local jurisdictions; regional planning where a multijurisdiction or multicounty organization provides planning services to its members; and statewide efforts in which state actors replace or supplement local planning operations.

\section{Concurrent Efforts}

Rather than a straightforward story of interlocal, horizontal efforts supplanting larger visions of regional governance, the current situation may be more nuanced. As Boyle and Mohamed (2007) find, an individual local government may be involved in multiple collaborative efforts: participating in small-scale collaborative efforts with neighboring governments; receiving assistance from its county and participating in countywide planning activities; and being a member of a regional council of governments. These multiple efforts should not necessarily be interpreted as a regional planning renaissance, however. For some communities, participating in multiple regional planning efforts is 
necessary because of dissatisfaction with the performance of one or more regional bodies (Boyle \& Mohamed, 2007). For others, participation in intergovernmental activities is mandated by either the state or federal government (such as with MPOs), giving them little choice in the matter (May, 1995).

Building on this body of literature, we hypothesize that a given local government may engage in horizontal collaborative planning activities, vertical collaborative planning activities, or both. The nature of collaboration undertaken by a local government will be a function of that unit's internal characteristics (e.g., population characteristics, governance capacity, political dynamics) as well as features of the spatial environment in which it is located, where that spatial environment may be defined at various geographic scales. Specifically, we test the following hypotheses.

H1: Local units of government whose neighbors are engaged in higher levels of intergovernmental collaboration are themselves more likely to collaborate.

As discussed above, the presence of neighboring units who engage in collaboration could contribute to a local government's likelihood of collaboration in two ways. First, the neighboring units may be partners with which a given local government can initiate collaboration (motivation), and second, the prevalence of collaboration may present a local government's leaders with more opportunities to join in ongoing collaborative efforts (opportunity). Either of these types of influence would increase the likelihood of the unit collaborating, but possibly in different ways.

$\mathrm{H} 2$ : Motivation is a stronger determinant of horizontal collaboration, while opportunity is a stronger determinant of vertical collaboration.

We expect that a local jurisdiction will be more likely to initiate horizontal collaboration, at least in part because such interlocal collaboration may be more pragmatically driven (such as solving a particular land use problem that spills over borders or cutting costs). Local government officials thus have an incentive to approach their neighbors to pursue mutually beneficial collaborative solutions to those problems. By contrast, we expect vertical collaboration to be less transactional and more focused on large-scale regional issues such as preserving open space. A single city or township may see less direct benefit to initiating such large-scale regional efforts and instead may prefer to wait for others-especially counties and regional actors - to initiate them.

H3: Communities who engage in horizontal collaboration are no less likely to engage in vertical collaboration and vice versa: the two are not substitutes for one another.

Horizontal and vertical collaboration serve different purposes and are motivated by different considerations. For example, in the area of land use planning, we expect that local governments pursue horizontal collaboration when they have certain resources and capabilities such as a farmland preservation initiative, an economic development program, or a professionalized planning department, when they have multiple neighbors who can serve as potential partners, and/or when land use problems they confront are characterized by spillover across neighboring jurisdictions or solutions that would benefit from economies of scale. They pursue vertical collaboration when they lack funding or professional or technical capacity, when their land use problems are shared by the region as a whole, or when they have attempted to solve an issue through horizontal collaboration and the effort has failed. In other words, horizontal and vertical collaboration are solutions to different kinds of problems and will make sense under different circumstances. That said, the two forms of collaboration may not be entirely independent. Once communities start to collaborate either vertically or horizontally, they will experience the benefits of collaboration first-hand and may be more likely to consider further collaboration — of either type-with different partners and/or on different issues.

\section{Land Use Planning Collaboration}

For this article, we test our hypotheses in the context of land use planning collaboration. In the early 1990s, the "new regionalism" spread to land use planning (Wheeler, 2002). Planners hoped that 
a regional approach would better solve some of the field's most pressing problems, such as sprawl, central city decline, inequitable distribution of resources, and environmental degradation (Burnley \& Murphy, 1995; Katz, 2000; Powell, 2000; Rusk, 2000). All of these problems are larger than any single jurisdiction (and many are "wicked" in nature) (David, 2008, p. 73), so scholars theorized that a regional approach would succeed in addressing these problems in ways that an individual, fragmented approach could not (Calthorpe \& Fulton, 2001).

Of course, the idea of regional planning has long had its skeptics, including Jane Jacobs, who famously said, "A region is an area safely larger than the last one to whose problems we found no solution" (Jacobs, 1961, p. 410). Large-scale regional planning successes have been few, due at least in part to the individualistic political culture in the United States, which plays out as a reluctance on the part of states to exercise their power over local governments, and on the part of local governments to give up their own devolved powers (Basolo, 2003; Norris, 2001). Therefore, with a few notable exceptions, most regional planning efforts in the United States are small in scale and voluntary in nature. In short, they look much like other common types of intergovernmental collaboration, which include the provision of both routine (such as water and sewer) and emergency (such as police and fire) services (Feiock, 2008).

Collaboration around land use planning differs from collaboration to provide these types of services in one important way, however: planning is considered a lifestyle function rather than a systems maintenance governmental function. Several studies find that local governments face greater challenges in creating collaborative relationships around lifestyle functions, since such functions are often values-dependent, involve questions of equity, and may create winners and losers (Gainsborough, 2002; Howell-Moroney, 2008; Williams, 1967). So, by focusing on this form of collaboration, we may be understating the prevalence of local government collaboration in general.

What might collaboration around land use look like? Horizontal efforts could range from the most basic sharing of plans with neighbors and with the county, to more intentional but less formal activities such as regular meetings between individual officials around particular land use challenges, to shorter-term joint projects to address land use in a particular area or corridor, to long-term formal arrangements such as the formation of a joint planning commission. Vertical efforts could include a regional council of governments that takes on a planning function, or a county-level planning commission or planning agency that produces plans for multiple subunits. As we discuss in our hypotheses, communities are likely have to different reasons for engaging in horizontal versus vertical collaboration. Our study does not attempt to make a normative judgment about which types of collaboration are better or worse (formal/informal, horizontal/vertical): different forms may be appropriate in different settings, so we do not privilege certain types of collaboration in our analysis.

\section{Collaboration in Michigan}

In Michigan, the subject of our analysis, there are both regulatory and cultural barriers to collaboration and regionalism. Although state statutes allow intergovernmental collaboration in many cases, the specifics of the regulations limit the potential financial benefit to communities that choose to engage in shared service agreements or other forms of collaboration that are designed to save money (McGee \& Trebilcock, 2007). Michigan's present-day township boundaries largely follow those set out by the surveyors of the Northwest Ordinance in the eighteenth century. Although Michigan's high degree of fragmentation (the number of local governments is second only to Pennsylvania) provides many potential partners with whom to collaborate, Michigan is also considered a strong home rule state, in which local governments are granted broad powers to address local issues (Citizens Research Council, 1994). Unlike in many southern and western states, county governments only have power over planning and zoning if their subunits choose not to exercise those powers themselves. This fragmentation and tradition of local political independence both contribute to an individualistic attitude among local governments (Jacobs, 2003). In addition, in recent decades, Michigan has been one of the most racially segregated states; at the time of the 2000 Census, Michigan was home to five of the 25 most segregated metropolitan areas in the United States (Schneider, 2003). Racial and economic segregation has led to mistrust between urban centers and their surrounding smaller 
cities and townships, where one might otherwise expect see collaboration around shared regional goals. These structural and political issues make collaboration, and especially collaboration around a lifestyle function like land use planning, particularly challenging in Michigan. To be sure, such efforts exist, but they exist in an unsupportive state milieu. To make matters more difficult, unlike states such as Oregon and Florida, which have strong state leadership on land use planning (Burby \& May, 1997), Michigan enables but does not require its county subunits to plan. This combination of state-level indifference to collaboration and local governmental independence is why, as we state in our hypotheses, we expect to see such strong spatial relationships between neighbors' collaborative activity, both vertical and horizontal. The types of relationships that are able to overcome the state's climate of local inertia and intergovernmental mistrust are location-specific, and, as such, are expected to exert a stronger influence on closer neighbors.

\section{DATA}

We test these hypotheses about the extent and nature of land use planning collaboration with data from the fall 2010 Michigan Public Policy Survey (MPPS). ${ }^{3}$ MPPS is a semi-annual survey of Michigan local government officials administered by the University of Michigan's Center for Local, State, and Urban Policy (CLOSUP), in partnership with the Michigan Municipal League, the Michigan Townships Association, and the Michigan Association of Counties. For each wave of the survey, mail or email invitations are sent to the top elected and appointed official of each of Michigan's 1,856 general-purpose local governments. Each official has the option of completing the approximately 30-minute survey online, on hard copy, or over the phone. Several follow-up contacts are made to increase response rates. Usable responses were received from 1,176 unique local governments $(64 \%)$ on the fall 2010 wave of the survey. ${ }^{4}$

The fall 2010 MPPS contained questions that allow us to investigate the extent and character of collaborative land use planning among Michigan local governments as well as the factors that influence that collaboration. To measure the extent of land use collaboration, we use a question that asked respondents to indicate the extent of their jurisdiction's collaboration with other governments in providing fourteen different types of services. One of the possible services was land use planning and/or zoning; respondents were allowed to indicate we do not collaborate at all, we collaborate somewhat, we collaborate a great deal, and don't know. We coded responses 0 for not at all, 1 for collaborate somewhat, and 2 for collaborate a great deal. Don't know responses were dropped, as were records on which the respondent did not indicate any value. On this question, the collaborative partner's identity was not defined, so responses could include horizontal collaboration, vertical collaboration, or both.

The fall 2010 MPPS also included a question that asked respondents with whom their jurisdiction collaborates. Response options include state, county, city, township, village, K-12 school district, higher education institution, regional organization, and other. Respondents were instructed to check all that apply. This question allows us to identify instances of horizontal collaboration (when a jurisdiction collaborates with a city, township, village, or K-12 school district), vertical collaboration (with the state, county, or regional organization) and both. However, the question does not specify land use planning, and so our inferences from analyses of that question apply to collaboration in general, and not land use collaboration specifically. ${ }^{5}$

In addition, the fall 2010 MPPS asked a question about the mechanisms by which jurisdictions entered into collaborative relationships. Respondents were asked whether, in the past two years, they approached other governments about formal collaborative efforts, whether they were approached by another government about collaboration, or neither. Conceptually, we can think about approaching another government as indicating a jurisdiction's proactive motivation for collaboration, and being approached by another unit as reflecting an existing opportunity for collaboration. This question, like the one about collaborative partners above, was not limited to land use collaboration. Regional planning was offered as an example of the type of collaboration the respondents were to consider, but responses are likely to include information about other forms of collaboration as well, and so again, our inferences from analyses of this question apply to collaboration in general. 
TABLE 1

Descriptive Statistics, Fall 2010 Michigan Public Policy Survey

\begin{tabular}{|c|c|c|c|c|c|}
\hline Variable & $N$ & Mean & Std Dev & Min & Max \\
\hline Extent of collaboration & 656 & 0.86 & 0.72 & 0 & 2 \\
\hline Horizontal & 1027 & 0.67 & 0.47 & 0 & 1 \\
\hline Vertical & 1027 & 0.37 & 0.48 & 0 & 1 \\
\hline City & 1027 & 0.19 & 0.39 & 0 & 1 \\
\hline $\operatorname{Ln}(P o p)$ & 1027 & 7.93 & 1.19 & 2.30 & 12.20 \\
\hline$P I D$ & 1027 & 2.42 & 2.21 & 0 & 7 \\
\hline$B A \%$ & 1027 & 0.10 & 0.061 & 0.014 & 0.38 \\
\hline Medlnc & 1027 & 43621.47 & 13361.32 & 20192 & 170790 \\
\hline MedPTax & 1027 & 1165.46 & 663.97 & 326 & 10001 \\
\hline MedAge & 1027 & 38.51 & 5.17 & 17.9 & 57.5 \\
\hline Black \% & 1027 & 0.021 & 0.065 & 0 & 0.78 \\
\hline Dem \% & 1027 & .050 & 0.10 & 0 & 0.99 \\
\hline Motivation & 1015 & 0.53 & 0.50 & 0 & 1 \\
\hline Opportunity & 1015 & 0.43 & 0.50 & 0 & 1 \\
\hline Neighbors_Collab & 940 & .089 & 0.56 & 0 & 2 \\
\hline County_Collab & 728 & 0.91 & 0.73 & 0 & 2 \\
\hline$Z\left(G i^{*}\right) \_18 k$ & 656 & -0.074 & 1.27 & -2.91 & 4.031 \\
\hline$Z\left(G i^{*}\right)-40 k$ & 656 & -0.15 & 1.59 & -3.98 & 3.74 \\
\hline$Z\left(G i^{*}\right) \_120 k$ & 656 & -0.21 & 2.37 & -5.73 & 3.063 \\
\hline
\end{tabular}

Finally, the fall 2010 MPPS includes FIPS codes as geographic identifiers for each respondent's jurisdiction. ${ }^{6}$ We merged in census information on each jurisdiction's population from the 2000 census (e.g., total population, median household income, median property tax, median age, percent black, percent with a bachelor's degree) as well as jurisdiction-level vote returns from the 2008 presidential election as a proxy for the citizenry's partisanship. We then created a shapefile in ArcGIS that treats the survey responses, demographic characteristics and partisanship variables as jurisdiction attributes. ${ }^{7}$ Table 1 reports descriptive statistics.

\section{METHODOLOGY AND RESULTS}

Our analyses involve identifying spatial patterns of responses in the MPPS data, testing for spatial effects at different geographic scales, and testing hypotheses about the factors that influence those patterns and effects. We utilize two separate but complementary empirical approaches: a spatial statistical approach (for identifying spatial patterns) and a multivariate regression approach (for testing hypotheses about the factors that influence patterns of collaboration).

\section{Identifying Patterns of Collaboration}

Spatial statistics can tell us whether and where spatial patterns or interdependencies are occurring in our data. To answer the first question (whether spatial interdependencies are occurring), we compute the Getis-Ord General G statistic in ArcGIS 10 (Getis \& Ord, 1992). General G measures the degree of clustering of high or low values of a given variable or attribute within a study area. ${ }^{8}$ In our application, we use this statistic to test whether jurisdictions that report high (low) levels of collaboration are clustered spatially across the entire state. Our estimated value of General G is .031, which is significant at $p<.003$.

To answer the second question (where spatial interdependencies are occurring), we conduct a hot spot analysis. Hot spot analysis uses spatial statistical techniques to identify local clusters of values that are significantly further from the overall mean than we would otherwise expect. When these clusters have values that are significantly higher than expected, they are called hot spots. When the clusters have values that are significantly lower than expected, they are called cold spots. Our hot 
spot analysis is conducted by generating the Getis-Ord $\mathrm{G}_{i}{ }^{*}$ statistic for each city and village in our sample within ArcMap 10 (Getis \& Ord, 1992; ESRI Developer Network, 2011). ${ }^{9}$ ArcGIS generates a new field in the attribute table of Z-scores, which measure the statistical significance of the level of clustering around a given observation (city/township). The larger the Z-score (in absolute value), the less likely it is that the distribution of values is random. We performed hot spot analysis using each governmental unit's reported level of land use planning collaboration. ${ }^{10}$

One important consideration in hot spot analysis is the threshold distance. In general, a hot spot analysis picks up different patterns, and the units' Z-scores change, based on how the threshold distance is defined. The threshold distance is the theorized zone of influence. For any given feature (in this case, jurisdiction), neighbors' values within the distance band threshold are assumed to matter. The features outside this distance are assumed not to influence the feature in question. ${ }^{11}$ How should we choose a threshold distance? There are several different ways to generate this value. First, if we do not specify a threshold distance, the program will choose the smallest distance at which each feature has at least one neighbor (either from point to point or, for lines and polygons, from centroid to centroid). However, using the default distance threshold lets the data, rather than any theory or hypothesis, drive the analysis. In addition, the default threshold distance is strongly influenced by the presence of missing data. For example, when we removed polygons with missing data from our shapefile, the default threshold distance increased by about two miles, or about $9 \%$.

Another way to choose a threshold distance is to run iterations of the test for spatial autocorrelation with increasingly large threshold distances until the overall Z-score seems to peak (there may be more than one peak), and use that distance for the hot spot analysis. Again, though, the distance threshold at which the Z-score peaks may not be theoretically meaningful.

We argue that the best way to choose a threshold distance is to ground that choice in theory or in the study's assumptions. In our study, the literature led us to expect to see influences on collaboration at three levels: interlocal (subcounty), county, and multicounty region. We therefore used three different threshold distances in three separate hot spot analysis runs: roughly 11 miles (18,000 meters), 25 miles (40,000 meters), and 75 miles (120,000 meters). Eleven miles is meant to reflect interlocal collaboration. We generated this distance by doubling the mean distance between city and township polygon centroids. Since township sizes vary quite a bit in Michigan, especially in the Upper Peninsula, we needed to double the mean distance to collect enough neighbors for each unit. Even so, some units still lacked any neighbors, which would have made the results of the analysis unreliable. For this smallest distance, then, we used a spatial weights matrix with a threshold distance of 18,000 meters, but also specified that each unit must have at least two neighbors. In cases where the nearest neighbors are more than 18,000 meters away, the program overrides the threshold distance to collect at least two neighbors. As mentioned in the preceding paragraph, the more missing data there are, the farther the tool has to go to find enough neighbors to conduct the analysis, so in theory if our response rate had been higher on this question, we would have been able to use a shorter threshold distance.

We generated the county-level distance of 40,000 meters by taking the mean centroid-to-centroid distance of the county polygons. The regional-level threshold distance of 120,000 meters is thus meant to reflect at least a tri-county area. As we discuss in the next section, we found evidence of spatial effects at each of these levels, but with very different patterns.

Figure 1 reports the results of the hot spot analysis. As expected, we find evidence of land use planning collaboration at all three of the levels we tested: interlocal, county, and regional. The patterns at each level look very different, however. At the interlocal level, reported in Panel A, we see scattered hot spots of collaboration around the state. Some are identifiable as specific interlocal efforts. For example, the Traverse City area is known for its collaborative efforts, especially the Grand Traverse Commons Joint Planning Commission. The red square to the southwest of Ann Arbor is Freedom Township, which is part of the Southwest Washtenaw Council of Governments, a subcounty intergovernmental organization that runs a joint planning commission. The hot spot due north of Lansing likely represents the communities involved in the Gratiot County Regional Excellence and Transformation Plan (GREAT), which each of the subunits have adopted as their own plan. There are also some large areas of interlocal collaboration west of Lansing, probably 


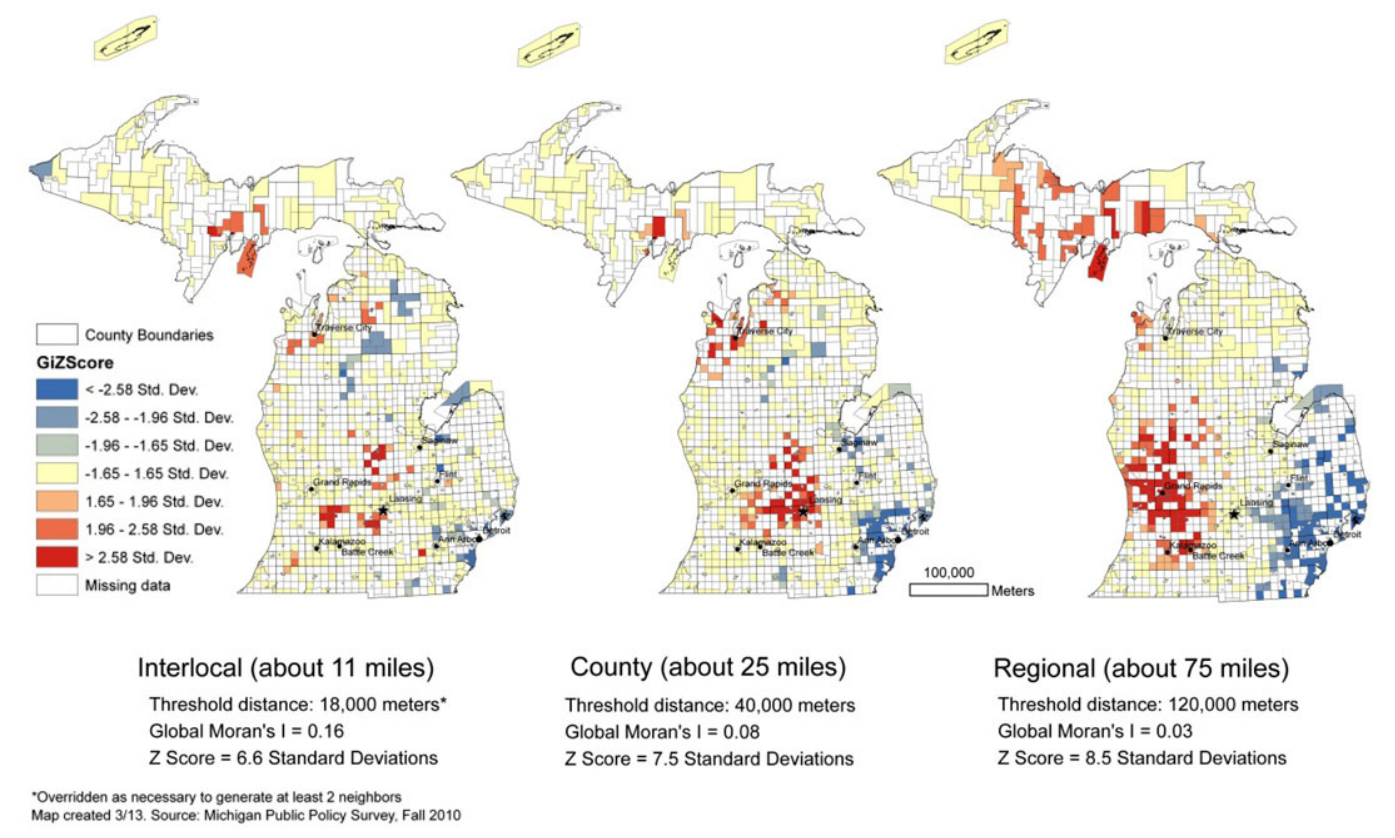

\section{FIGURE 1}

\section{Hot Spot Analysis (Getis-Ord G*) of Q5A_R: Extent of Jurisdiction's Collaboration Around Land Use Planning}

representing the Barry County Joint Planning Alliance. The hot spot in the central Upper Peninsula corresponds quite closely to the boundaries of the Central Upper Peninsula Planning and Development Regional Commission (CUPPAD).

Fewer cold spots appear in the interlocal-level data than in the county and regional analyses described below. The areas with the most pronounced cold spots are north central Michigan and southeast Michigan. The seven-county Southeast Michigan Council of Governments (SEMCOG) essentially makes up metropolitan Detroit. Although SEMCOG is a sophisticated regional organization, the Detroit Metro area is known for contentious politics between city and suburbs, and a historic lack of trust and collaboration (Browne \& VerBurg, 1995; Jacobs, 2003). Therefore, this cold spot is not surprising.

County-level spatial analysis of collaboration around land use in Panel B turns up slightly different patterns. The Traverse City metro area and Gratiot and Barry counties show up again as hot spots. In this map, however, some more substantial cold spots emerge as well, around Saginaw and notably throughout much of Southeast Michigan. Local governments in these areas are far below the state mean in terms of conducting countywide land use planning efforts.

The results of the regional analysis in Panel C are particularly striking. West Michigan and the central Upper Peninsula appear as region-wide hot spots. The west Michigan hot spot likely represents the Grand Valley Metropolitan Council, focused around Kent County (location of the City of Grand Rapids), which is a 20 -year-old voluntary regional government that has been "reasonably effective" at providing a vehicle for intergovernmental interactions (Visser, 2004, p. 56) and combating sprawl with an urban utility boundary (Dutzik \& Imus, 2002). Southeast Michigan and the "Thumb" area are major cold spots, even considering the low response rate from the Thumb municipalities. As we mention above in the results of the interlocal analysis, southeast Michigan is known for its historic lack of intergovernmental collaboration and regional planning. The Thumb area townships are generally low-capacity, and the regional culture is generally suspicious of government, and in particular any action that leans toward collectivism (for example, the Thumb is the traditional home of the Michigan Militia, a right-wing paramilitary group) (Freedman, 2008). A cold spot here fits with what we know about attitudes toward regional collaboration in the area. 


\section{Testing Hypotheses About Spatial Influences on Collaboration}

The spatial statistical approach shows whether and where collaboration is occurring, but it is limited in what it can tell us about how various factors influence those patterns. Multivariate regression analysis allows the researcher to test the marginal effect of one or more factors (independent variables) on an outcome (dependent variable) while controlling for or holding constant the potential effects of other factors. In the current context, we are interested in testing hypotheses about whether the spatial environment (independent variables) of a given jurisdiction affects the extent and form of land use planning collaboration (dependent variables) it undertakes, controlling for the jurisdiction's internal characteristics.

We capture a jurisdiction's spatial environment by creating several variables from the MPPS survey. To capture the most local spatial environment, we identify each jurisdiction's neighbors by generating a spatial weights matrix in ArcGIS 10 with a weight of 1 assigned to each neighbor (edges and borders) and of 0 to all others. We then convert this weights matrix to a table, export the table and merge it into the MPPS survey database, and collapse the survey responses in Stata to compute the mean value of each unit's neighbors' reported level of collaboration. ${ }^{12}$ The number of neighbors ranges from 1 to 12 , with a mean of $6.44 .{ }^{13} \mathrm{We}$ also include the jurisdiction's Z-score from the hot spot analysis, using the smallest (18,000 meter) threshold distance, as an additional measure of the jurisdiction's most local spatial environment.

To capture county-level environment, we identify each jurisdiction's county and record the county's response to the same survey question regarding level of land use collaboration. ${ }^{14}$ Interestingly, we observe that, on average, counties report a higher level of collaboration than individual jurisdictions, with a mean value of 0.97 (on the same 0-2 scale) compared to the local governments' mean value of 0.85 . We further capture county-level spatial environment with the jurisdiction's Z-score from the hot spot analysis using the 40,000-meter threshold distance.

To capture regional-level spatial environment, we include the jurisdiction's hot spot analysis Zscore using the 120,000-meter distance band. Unfortunately, the MPPS sample did not include any regional organizations (e.g., COGs, RCs, MPOs), so we do not have direct (reported) measures of collaboration at the regional level.

The regression analyses then take a given city or township's response to the land use collaboration and horizontal/vertical collaboration questions as the dependent variables, and the various spatial environment measures as the main independent variables. The jurisdiction's population characteristics and vote returns serve as control variables.

Table 2 reports the results of a set of multivariate regression analyses that allows us to test $\mathrm{H} 1$ (that spatial context affects a jurisdiction's level of collaboration). The table reports six separate regression analyses. In each model, the dependent variable is a local government's reported level of land use collaboration. This variable takes on three values: 0 (no collaboration), 1 (some collaboration), and 2 (a great deal of collaboration). Since our dependent variable is discrete and ordinal, the assumptions of standard ordinary least squares (OLS) regression are violated. We therefore estimated the models using generalized ordered logistic regression, which allows the researcher to test for whether the proportional odds/ parallel lines assumptions of ordered logistic regression are met. ${ }^{15,16}$

Each model includes a different set of independent variables. Model 1 is our baseline model which includes only jurisdiction-level demographic and political characteristics. The results in Model 1 show that jurisdiction-level characteristics have some impact on a city or township's extent of collaboration on land use planning. All else constant, cities report lower levels of collaboration than townships. Cities and townships with higher property taxes and older residents report lower levels of collaboration, while those with a more educated population report higher levels.

Model 2 adds the Motivation and Opportunity variables. Both are positive and significant, suggesting that jurisdictions that seek out collaborative opportunities (Motivation) and that are approached by potential collaborative partners (Opportunity) engage in higher levels of collaboration. Of the two, the effect of Opportunity is larger and more precisely estimated (i.e., has a smaller standard error).

Model 3 captures the jurisdiction's collaborative environment at various spatial scales by including the reported mean level of collaboration of the jurisdiction's neighbors (interlocal scale) and the 
TABLE 2

Extent of Collaboration: Generalized Ordered Logit Results, Partial Proportional Odds

\begin{tabular}{|c|c|c|c|c|c|c|}
\hline & Model 1 & Model 2 & Model 3 & Model 4 & Model 5 & Model 6 \\
\hline City & -.53 & $-.51^{* *}$ & $-.60^{* *}$ & -.25 & -.18 & $-.41^{*}$ \\
\hline $\operatorname{Ln}(P o p)[1]$ & .034 & -.020 & .043 & .15 & .11 & 025 \\
\hline $\operatorname{Ln}(P o p)[2]$ & -.17 & $-.25^{* *}$ & $-.39 * *$ & -.14 & -.17 & $-.22^{*}$ \\
\hline$P I D$ & .044 & .044 & .037 & $.066^{*}$ & .055 & .049 \\
\hline$B A \%[1]$ & $10.69^{* * *}$ & $10.096^{* * *}$ & $6.90 * *$ & 3.72 & $4.42^{*}$ & $6.70^{* *}$ \\
\hline$B A \%[2]$ & $5.19^{* *}$ & $5.13^{* *}$ & & -1.54 & -.67 & 1.87 \\
\hline Medlnc & -.000016 & -.000014 & $-7.86 e-06$ & $-5.66 e-06$ & $2.15 e-06$ & $-1.58 \mathrm{e}-06$ \\
\hline MedPTax & $-.00071^{* *}$ & $-.00073^{* *}$ & $-.00076^{* *}$ & -.00014 & -.00035 & -.00046 \\
\hline MedAge & $-.046^{* *}$ & $-.045^{* *}$ & $-.055^{* *}$ & -.017 & -.014 & $-.034 *$ \\
\hline Black \% & -.71 & -.77 & -2.39 & -.32 & -.28 & -.78 \\
\hline Dem \% & -.23 & -.40 & -.60 & -.48 & -.0016 & .30 \\
\hline Motivation & & $.36^{* *}$ & $.42^{* *}$ & .24 & $.29 *$ & $.32 *$ \\
\hline Opportunity & & $.41^{* *}$ & $.44^{* *}$ & $.40^{* *}$ & $.43^{* *}$ & $.40^{* *}$ \\
\hline Neighbors Collab & & & $.51^{* *}$ & & & \\
\hline County Collab [1] & & & .15 & & & \\
\hline County Collab [2] & & & $.51^{* *}$ & & & \\
\hline$Z(G i *) \_18 k$ & & & & $.90^{* * *}$ & & \\
\hline$Z(G i *) \_40 k$ & & & & & $.42^{* * *}$ & \\
\hline$Z(G i *) \_120 k$ & & & & & & $.14^{* * *}$ \\
\hline Constant [1] & $2.76^{* *}$ & $2.78^{* *}$ & 2.36 & .17 & -.23 & 1.20 \\
\hline Constant [2] & $2.83^{* *}$ & $2.95^{* *}$ & $3.26^{*}$ & .46 & .24 & 1.49 \\
\hline$\chi^{2}$ & 7.44 & 10.23 & 11.31 & 11.04 & 11.15 & 11.64 \\
\hline Prob $>\chi^{2}$ & .38 & .33 & .42 & .35 & .35 & .31 \\
\hline Pseudo $R^{2}$ & .036 & .044 & .073 & .16 & .08 & .053 \\
\hline$N$ & 656 & 651 & 438 & 651 & 651 & 651 \\
\hline
\end{tabular}

Note: ${ }^{*} p<.10,{ }^{* *} p<.05,{ }^{* * *} p<.01$.

reported collaboration of the jurisdiction's county (county scale). The effects of collaboration by a jurisdiction's immediate neighbors and by its county are both positive and significant. The odds ratio associated with a one-unit increase in neighbors' collaboration is 1.66. In other words, as the reported collaboration of a city's or township's neighbors increases by one unit, the odds of a jurisdiction's own collaboration moving to the next higher reported level (i.e., from 0 to 1 or from 1 to 2 ) is 1.66 . This effect holds even after we account for the various drivers of collaboration that are internal to the jurisdiction. The effect of county-level spatial environment has a positive and significant effect on the probability of moving from some collaboration to a great deal of collaboration, again controlling for jurisdiction-level factors.

Models 4 through 6 include the jurisdiction's $\mathrm{G}_{i} * \mathrm{Z}$-score from the hot spot analyses with threshold distances set at 18,000 meters (interlocal scale), 40,000 meters (county scale) and 120,000 meters (regional scale), respectively. ${ }^{17}$ We see that all of these effects are positive and highly significant, suggesting that being located in a spatial environment in which a jurisdiction's neighbors, county, and region are engaging in high levels of collaboration leads that jurisdiction to itself collaborate. Of the three spatial scales, the effect of being in a local hot spot (Model 4) is the largest. Finally, when the hot spot variables are included in the models, the effects of most of a jurisdiction's internal characteristics are no longer significant.

The results reported in Table 2 provide support for $\mathrm{H} 1$, that a local government's decision to engage in intergovernmental collaboration is affected by its spatial context at several geographic scales. Due to how the survey question was framed, however, it does not tell us whether those decisions involve horizontal collaboration, vertical collaboration, or both. The following analyses leverage the additional questions on the fall 2010 MPPS to test $\mathrm{H} 2$, whether motivation and opportunity influence different types of collaboration, as well as $\mathrm{H} 3$, whether horizontal and vertical collaborative endeavors are complements to or substitutes for one another. 
TABLE 3

Collaboration Partners: Percent of Jurisdictions Reporting, Michigan Local Governments

\begin{tabular}{lcc}
\hline Partner & Percent of Cities Reporting $(N=173)$ & Percent of Townships Reporting $(N=750)$ \\
\hline State & 11.56 & 2.80 \\
County & 51.44 & 28.13 \\
City & 47.40 & 23.87 \\
Township & 63.58 & 50.80 \\
Village & 10.98 & 14.80 \\
K-12 School dist & 27.75 & 7.33 \\
Higher ed inst & 5.78 & 0.93 \\
Regional org & 22.54 & 8.00 \\
\hline
\end{tabular}

TABLE 4

Patterns of Horizontal and Vertical Collaboration, Michigan Local Governments

\begin{tabular}{lcccr}
\hline & & \multicolumn{2}{c}{ Vertical } & Total \\
\cline { 3 - 5 } & & $\mathrm{N}$ & $\mathrm{Y}$ & 334 \\
\hline Horizontal & $\mathrm{N}$ & 302 & 32 & 693 \\
& $\mathrm{Y}$ & 340 & 353 & 1027 \\
& Total & 642 & 385 & 100 \\
\hline
\end{tabular}

Table 3 reports the number of cities and townships in the MPPS sample that reported collaborating with each of the eight types of partners. ${ }^{18}$ Collaborating with state, county, and regional organization partners is considered a vertical form of collaboration; city, township, village, and K-12 school district partners are considered horizontal forms. We see that the most frequent collaboration partners for both types of jurisdictions are townships, counties, and cities. Thus, cities and townships alike are engaging in both horizontal and vertical collaboration, though cities report greater frequencies of collaboration with all types of partners (except villages). ${ }^{19,20}$

Table 4 reports the number of cities and villages in the MPPS sample that report some incidence of horizontal collaboration, vertical collaboration, neither, and both. The table shows a great deal of heterogeneity among cities and villages in their approaches to collaboration. Roughly $30 \%$ report no collaboration at all; 33\% report horizontal only; 3\% report vertical only; and 34\% report both. These patterns provide preliminary evidence that the two forms of collaboration do not function as substitutes, but rather that communities pursue different forms of collaboration for different reasons. It is also interesting that we see nearly one-third of communities reporting only horizontal collaboration and one-third reporting both horizontal and vertical, but very few reporting only vertical collaboration. The multivariate analyses below explore these preliminary results in greater detail.

Tables 5 and 6 investigate the determinants of horizontal and vertical collaboration, respectively. The tables are organized much the same as Table 2, with the results of six separate regression analyses - containing the same independent variables as those in Table 2 - reported in each table's columns. In these tables, however, the dependent variables are whether or not the jurisdiction reported any horizontal or vertical collaboration, with Horizontal scored one if the respondent indicated partnering with a city, township, village or school district and scored zero otherwise, and with Vertical scored one if the respondent indicated partnering with a state, county, or regional organization and scored zero otherwise. Given our binary dependent variables, we employ logistic regression.

The logit coefficients for horizontal collaboration in Table 5 show that Motivation and Opportunity, as well as several internal characteristics, strongly affect the probability that a jurisdiction engages in collaboration with other local governments, while none of the spatial variables are significant in any of the models. In the baseline model in Column 1, cities, larger jurisdictions, those with more educated populations, and those with Democratic Party elected officials are more likely to engage in horizontal collaboration; those with higher property taxes are less likely. The effect of being a 


\section{TABLE 5}

Horizontal Collaboration, Logistic Regression Coefficients

\begin{tabular}{|c|c|c|c|c|c|c|}
\hline City & $1.20^{* * *}$ & $1.083^{* * *}$ & $1.20 * *$ & .99 & 0.95 & 0.93 \\
\hline $\operatorname{Ln}(P o p)$ & $0.41^{* * *}$ & 0.15 & 0.17 & -0.082 & -0.081 & -0.11 \\
\hline$P I D$ & $0.081^{* *}$ & $0.073^{*}$ & 0.066 & $0.15^{*}$ & $0.14^{*}$ & $0.14^{*}$ \\
\hline$B A \%$ & $9.56^{* * *}$ & $6.72^{* *}$ & $7.12^{* *}$ & -2.062 & -1.046 & 0.42 \\
\hline Medlnc & $6.49 e-06$ & 0.000016 & 0.000019 & $0.000063^{* *}$ & $0.000058^{* *}$ & $0.000057^{* *}$ \\
\hline MedPTax & $-0.00054^{* *}$ & $-0.00063^{* *}$ & -.00079 & 0.00010 & $1.59 \mathrm{e}-06$ & -0.00012 \\
\hline MedAge & -0.0020 & 0.0025 & 0.0077 & 0.024 & 0.021 & 0.015 \\
\hline Black \% & -1.84 & $-2.86^{*}$ & $-3.59^{*}$ & -2.85 & -2.94 & -3.13 \\
\hline Dem \% & 0.26 & 0.35 & -0.69 & 0.54 & 0.37 & 0.45 \\
\hline Motivation & & $1.88^{* * *}$ & $1.96^{* * * *}$ & $1.33^{* * * *}$ & $1.33^{* * *}$ & $1.35^{* * *}$ \\
\hline Opportunity & & $1.15^{* * *}$ & $1.30^{* * *}$ & $0.82^{* *}$ & $0.82^{* *}$ & $0.86^{* *}$ \\
\hline Neighbors Collab & & & -0.14 & & & \\
\hline County Collab & & & 0.16 & & & \\
\hline$Z(G i *) \_18 k$ & & & & 0.068 & & \\
\hline$Z(G i *) \_40 k$ & & & & & 0.029 & \\
\hline$Z(G i *) \_120 k$ & & & & & & -0.14 \\
\hline Constant & $-3.41^{* * *}$ & $-2.80^{* *}$ & -2.58 & -1.97 & -1.56 & -1.10 \\
\hline$R^{2}$ & .11 & .25 & .27 & .13 & .13 & .13 \\
\hline$N$ & 1,027 & 1,015 & 666 & 651 & 651 & 651 \\
\hline
\end{tabular}

Note: ${ }^{*} p<.10,{ }^{* *} p<.05,{ }^{* * *} p<.01$.

\section{TABLE 6}

Vertical Collaboration, Logistic Regression Coefficients

\begin{tabular}{|c|c|c|c|c|c|c|}
\hline City & $0.61^{* *}$ & $0.56^{* *}$ & $0.80^{* *}$ & 0.18 & 0.27 & 0.30 \\
\hline $\operatorname{Ln}(P o p)$ & $0.43^{* * *}$ & $0.27^{* *}$ & $0.25^{* *}$ & $0.24^{* *}$ & $0.27^{* *}$ & $0.29 * *$ \\
\hline$P I D$ & 0.016 & 0.0080 & 0.020 & -0.0040 & -0.0014 & -0.00021 \\
\hline$B A \%$ & $9.39^{* * *}$ & $7.34^{* * *}$ & $6.27^{* *}$ & $8.61^{* * *}$ & $6.68^{* *}$ & $6.083^{* *}$ \\
\hline Medlnc & $-0.000020 *$ & $-0.000018^{*}$ & $-1.12 \mathrm{e}-06$ & $-0.000032^{* *}$ & $-0.000026^{* *}$ & $-0.000026^{* *}$ \\
\hline MedPTax & $-0.00061^{* *}$ & $-0.00059^{* *}$ & $-0.00093^{* *}$ & $-0.00059^{*}$ & -0.00045 & -0.00038 \\
\hline MedAge & -0.014 & -0.012 & 0.00092 & -0.022 & -0.012 & -0.0098 \\
\hline Black \% & 0.55 & 0.41 & 1.46 & 2.11 & 2.31 & 2.47 \\
\hline Dem \% & -0.43 & -0.69 & -1.091 & $-2.13^{*}$ & -1.92 & $-2.050^{*}$ \\
\hline Motivation & & $1.0041^{* * * *}$ & $0.96^{* * *}$ & $0.039^{* *}$ & $0.36^{* *}$ & $0.34^{*}$ \\
\hline Opportunity & & $0.76^{* * *}$ & $0.82^{* * *}$ & $0.48^{* *}$ & $0.47^{* *}$ & $0.45^{* *}$ \\
\hline Neighbors Collab & & & 0.065 & & & \\
\hline County Collab & & & 0.18 & & & \\
\hline$Z(G i *) \_18 k$ & & & & -0.037 & & \\
\hline$Z(G i *) \_40 k$ & & & & & 0.074 & \\
\hline$Z(G i *) \_120 k$ & & & & & & $0.20^{* *}$ \\
\hline Constant & $-2.72^{* *}$ & $-2.16^{*}$ & $-2.78^{*}$ & 0.74 & -0.23 & -0.37 \\
\hline$R^{2}$ & .081 & .14 & .14 & .061 & .061 & .069 \\
\hline$N$ & 1,027 & 1,015 & 666 & 651 & 651 & 651 \\
\hline
\end{tabular}

Note: ${ }^{*} p<.10,{ }^{* *} p<.05,{ }^{* * *} p<.01$.

city and having a Democratic Party elected official are largely robust to the inclusion of the spatial variables.

In Column 2, we see that both Motivation and Opportunity are strong and significant, and remain so in the other models as well. Motivation is consistently larger, suggesting that jurisdictions that are actively engaging and seeking out partnerships with other local governments are more likely to undertake this form of collaboration.

In Columns 3-6, we see that none of the spatial effects are significant. Thus, in stark contrast to the strong and significant effects of all of the spatial environment variables on the extent of collaboration, 
there is no systematic effect of spatial collaborative environment on the likelihood of this particular form of collaboration. ${ }^{21}$

Table 6 reports comparable logit coefficients for our models of vertical collaboration. We observe some interesting similarities with Table 5. Many of the internal characteristics have similar effects in the baseline model, with cities, larger jurisdictions, those with more highly educated populations, and those with lower property taxes more likely to engage in both forms of collaboration. Also as in Table 5, most of the spatial effects are insignificant. An important exception is the regional (120,000meter) hot spot variable. Being part of a regional land use collaboration hot spot significantly affects the probability of vertical collaboration. Being part of a county-level hot spot is also positive but is not significant.

There are other important differences between Tables 5 and 6. Both Motivation and Opportunity are again significant in Table 6, but whereas Motivation had the stronger effect in the models of horizontal collaboration, the reverse is true for most of the models of vertical collaboration: being approached by other governments has a stronger effect on this form of collaboration than being the one who reaches out to others, at least once we account for being in a collaborative hot spot. In other words, vertical collaboration is a more top-down process than horizontal collaboration, and the data bear this out.

\section{DISCUSSION}

We frame our discussion in terms of the article's three hypotheses:

- H1: Local units of government whose neighbors are engaged in higher levels of intergovernmental collaboration are themselves more likely to collaborate.

- H2: Motivation is a stronger determinant of horizontal collaboration, while opportunity is a stronger determinant of vertical collaboration.

- H3: Communities that engage in horizontal collaboration are no less likely to engage in vertical collaboration: the two are not substitutes for one another.

In our tests of H1, all of the spatial effects are significant in the models of the extent of collaboration in Table 2, suggesting that they influence the amount of collaboration around land use, but less so the form of collaboration (as evidenced by the insignificant effects in Tables 5 and 6). Instead, internal characteristics are more important in the latter. So, the collaborative behavior of a community's neighbors influences whether and to what extent that community collaborates, but not necessarily with whom. There is one exception to this observation, however, which is that the extent of regional collaboration (hot spot at 120,000 meters) is a significant predictor in the model of vertical collaboration (Table 6). Given that the MPPS respondents all represent local units of government, by definition any collaboration they engage in at the regional level (above the county) is vertical in nature. From this perspective, this result is not surprising. It is somewhat surprising, however, that similar spatial effects are not apparent at the horizontal level. It is possible that these effects are complicated by horizontal collaboration between counties.

The question of motivation versus opportunity $(\mathrm{H} 2)$ produces particularly interesting results. Reporting that one's local officials approached others regarding collaboration (i.e., Motivation) and that one's jurisdiction was approached by officials from other jurisdictions (i.e., Opportunity) are both associated with higher levels of collaboration. In other words, either the presence of available partners or a culture of collaboration makes it more likely that a unit will collaborate. Opportunity is a stronger determinant of level of collaboration. Further, opportunity seems to be more associated with vertical collaboration than motivation does, while motivation is more strongly associated with horizontal collaboration. We interpret this result to mean that local governments are more likely to join an existing county or regional-led effort and are less likely to organize such an effort themselves. This is consistent with the observation that higher levels of government are more likely to have the resources to organize such an effort.

Finally, our analysis indicates that horizontal and vertical collaboration are more complements to rather than substitutes for each other $(\mathrm{H} 3)$. The bivariate correlation is just .40, and the determinants 
of vertical collaboration (Table 6) are quite different from those of horizontal collaboration (Table 5). For example, the roles of Motivation and Opportunity are reversed between the two-we discuss this difference in detail below. In other words, different kinds of communities engage in each type of collaboration, and there are many that do only one or the other. Anecdotally, many township residents and officials embrace the idea of limited government and local control. To these actors, horizontal collaboration might not have the same "big government" baggage as does vertical collaboration. Framing a collaborative effort as neighbors working together may be viewed as less contradictory to a culture of self-sufficiency than does getting involved in a regional, top-down planning effort.

\section{CONCLUSION}

This article contributes to our understanding of intergovernmental collaboration in three important ways: we assess factors influencing both vertical and horizontal collaboration simultaneously; we analyze both internal jurisdictional and external (regional cultural) factors influencing collaboration: and we distinguish between motivation and opportunity as drivers of collaboration. In all of these analyses, we identify previously overlooked spatial patterns of collaboration. Despite Michigan's reputation for parochialism, we find considerable collaborative activity around land use in the state at each of three theoretically justified levels: interlocal, county-wide, and regional. We also find that the collaborative activity of neighboring communities around land use has a significant effect on whether a community will choose to engage in such planning efforts. Regional norms around collaboration seem to matter, as does the availability of partners. We demonstrate these spatial effects of regional land use planning through regression analysis, and even more strikingly in our spatial statistical analysis, where we identify hot spots and cold spots of collaborative land use planning.

One caveat to our analysis here is that, although certain areas of the state appear visually as hot spots of regional land use planning, it is important to keep in mind that what respondents report as high levels of collaboration in Michigan may be modest in comparison to collaborative efforts in states with stronger traditions of regional collaboration around land use. As Visser (2004) notes, "Michigan is noted for strong constitutional and state-level political support for local autonomy, powerful township governments legally capable of providing many urban services, and weak support for regional entities" (p. 54). Indeed, all of the collaborative efforts noted in the results section above are voluntary, making them especially vulnerable to changing political priorities.

Future analysis could expand and enhance the conclusions of this research in several ways. Additional survey research could be conducted asking respondents more specifically about which types of collaboration they undertake and involving which partners, in order to better understand the extent and nature of the many collaborative efforts identified in this study. Combined qualitative and quantitative research could help explain the directionality (motivation vs. opportunity) of types of collaborative relationships and how they function on the ground, as well as generate recommendations for making collaborative efforts more successful.

\section{ENDNOTES}

1 The third type of relationship, which may be called a consolidationist approach to vertical regional governance, creates an actual governmental structure that handles regional issues. It may even involve the expansion of central city boundaries through annexation or a city-county government consolidation (Savitch \& Vogel, 2000, p. 162).

2 The extent to which counties hold hierarchical powers relative to cities/townships, and hence are appropriately considered to be at a higher level within the hierarchy of governments, varies greatly across states. In Michigan, counties have autonomous land use planning authority, and may undertake planning functions on behalf of their cities and townships.

3 The Michigan Public Policy Survey is conducted by the University of Michigan's Center for Local, State, and Urban Policy, and a number of other sponsors. Any opinions, findings, and conclusions or recommendations expressed here are those of the author(s) and do not necessarily reflect the views of the funding organizations. 
4 A total of 3,502 invitations were sent, with 1,423 individual responses received, for an overall response rate of $41 \%$. For the analyses conducted in this study, only a single response from each jurisdiction-typically from the city manager or township clerk—was included.

5 Although this question did not specify the functional area of collaboration, land use planning was one of the most frequently reported areas of collaboration on the previous question. Only public safety functions (fire, 911, and police) were mentioned much more frequently. Land use planning was reported about as frequently as the related areas of economic development, parks and recreation, and utilities. Therefore, while we cannot isolate the specific partners for land use planning versus other collaborative activities based on this question, it is quite likely that many respondents had land use planning in mind when they answered this question.

6 We also include a measure of the respondent's partisanship (if reported) to capture the city/village government's partisan leaning.

7 Because our analyses involve mapping and analyzing spatial relationships between jurisdictions, we limit our data set to those cities and townships that comprise the U.S. Census Bureau's County Subdivision geography for Michigan. This geographic designation excludes villages since they geographically overlap townships (i.e., a given village resident is also a resident of an underlying township) and so (1) some information such as vote returns are not reported separately for villages, and (2) measuring geographic neighbors becomes highly ambiguous.

8 Specifically, $G=\frac{\sum_{i=1}^{n} \sum_{j=1}^{n} w_{i, j} x_{i} x_{j}}{\sum_{i=1}^{n} \sum_{j=1}^{n} x_{i} x_{j}}, \forall j \neq i$, where $x_{i}$ and $x_{j}$ are attribute values for units $i$ and $j$, and $w_{i, j}$ is the spatial weight between units $i$ and $j$.

9 Specifically, $G_{i}^{*}=\frac{\sum_{j=1}^{n} w_{i, j} x_{j}-\bar{X} \sum_{j=1}^{n} w_{i, j}}{\frac{s \sqrt{n\left[\sum_{j=1}^{n} w_{i, j}^{2}-\left(\sum_{j=1}^{n} w_{i, j}\right)\right]}}{n-1}}$, where $x_{j}$ is a is an attribute of unit $j, w_{i, j}$ is the spatial weight between units $i$ and $j, n$ is the total number of units, $\bar{X}=\frac{\sum_{j=1}^{n} x_{j}}{n}$ and $S=\sqrt{\frac{\sum_{j=1}^{n} x_{i}^{2}}{n}}-(\bar{X})^{2}$.

10 We also ran tests for global spatial autocorrelation (Moran's $I$ ), since hot spot analysis may not be appropriate for data with significant global spatial autocorrelation (Anselin, 1995, p. 97). In this case, however, there was no significant evidence of global spatial autocorrelation. For the threshold distances we used, the global Moran's $I$ statistic ranged from 0.16 to 0.03 , suggesting that $\mathrm{G}_{i} *$ is appropriate.

11 There are numerous options in the ArcGIS hot spot analysis tool for determining the nature of the spatial relationship. In this case, we used a fixed distance band with Euclidean distance.

12 We also construct measures of neighbors' population characteristics such as median household income, median property tax, and partisan composition, though none of these variables are significant in any of the analyses.

13 To construct measures of neighbors' level of collaboration, we can only include information from neighbors that completed the MPPS survey. The number of such neighbors ranges from 0 to 10 , with a mean number of responding neighbors of 4.46 .

14 County respondents to the MPPS were asked many of the same questions as city and township respondents, including those about their extent of collaboration, in addition to some unique questions as well. The county responses are not included in the main analyses.

15 Specifically, ordered logit requires that the slope coefficients are the same across each level of the dependent variable. We conducted generalized ordered logistic regression analyses in Stata 11 and tested for whether the models met this "parallel lines" assumption. In all six models, the slope coefficients are statistically indistinguishable across each level except for size $(\ln ($ Pop) ) and education (BA\%). In one model (Model 3), the county collaboration variable is found to violate the parallel lines assumption as well. The generalized ordered logistic regression operation in Stata constrains the coefficients that meet the assumption to be identical and reports separate coefficients for those that do not meet the parallel lines assumption. The results presented in Table 2 reflect these estimates. 
16 We also estimate the models using OLS and obtain similar results in terms of sign and significance. Because the underlying logit model takes on a different functional form than OLS, the magnitudes of the estimated coefficients are not comparable. Results of the OLS analyses are available from the authors upon request.

17 Due to high levels of multicollinearity between the spatial environment variables, we are not able to include all of the measures in a single model.

18 Recall that this question refers to collaboration in general, and not to land use planning collaboration specifically. This table does not include the other option.

19 This pattern is likely due to the unique relationship between villages and townships in Michigan. Townships are the state's basic unit of local government. When a village incorporates, the underlying township boundaries remain and residents pay taxes to and receive services from both the village and the township. As such, townships and villages may find it beneficial to coordinate their service delivery.

20 Note that this greater frequency of collaboration by cities is diminished in the multivariate analyses in Table 2 once we control for other factors such a jurisdiction's demographic, political, and spatial characteristics.

21 This lack of significance may be due, in part, to the mismatch between the dependent variable, which refers to horizontal and vertical collaboration in general, and the spatial environment variables, which ask specifically about collaboration around land use planning.

\section{REFERENCES}

Anselin, L. (1995). Local indicators of spatial autocorrelation-LISA. Geographical Analysis, 27(2), 93-115.

Basolo, V. (2003). US regionalism and rationality. Urban Studies, 40, 447-462.

Boyle, R., \& Mohamed, R. (2007). State growth management, smart growth and urban containment: A review of the US and a study of the heartland. Journal of Environmental Planning and Management, 50, 677-697.

Browne, W. P., \& VerBurg, K. (1995). Michigan politics and government: Facing change in a complex state. Lincoln: University of Nebraska Press.

Burby, R. J., \& May.P. J. (1997). Making governments plan: State experiments in managing land use. Baltimore: Johns Hopkins University Press.

Burnley, I. H., \& Murphy, P. A. (1995). Exurban development in Australia and the United States: Through a glass darkly. Journal of Planning Education and Research, 14, 245-254.

Calthorpe, P., \& Fulton, W. (2001). The regional city: Planning for the end of sprawl. Washington, DC: Island Press.

Carr, J. B., Gerber, E. R., \& Lupher, E. (2009). Explaining horizontal and vertical cooperation on public services in Michigan: The role of local fiscal capacity. In G. Sands \& R. Jelier (Eds.), Metropolitan affairs in Michigan: Case studies and best practices (pp. 207-236). East Lansing: Michigan State University Press.

Citizens Research Council. (1994). Michigan Constitutional Issues. Report No. 313-09. Retrieved June 1, 2013, from www.cremich.org.

David, N. P. (2008). Why cooperate? An evaluation of the formation and persistence of voluntary regional land use cooperative arrangements in Michigan (unpublished doctoral dissertation). University of Michigan, Ann Arbor. Retrieved March 9, 2011, from lib.umich.edu

Dutzik, T. \& Imus, B. (2002). Coordinated planning in Michigan: Three case studies. Ann Arbor, MI: PIRGIM Education Fund.

ESRI Developer Network. (2011). Hot spot analysis (Getis-Ord Gi*)(Spatial statistics). Retrieved August 1, 2011, from http://edndoc.esri.com/arcobjects/9.2/net/shared/geoprocessing/spatial_statistics_tools/hot_spot_analysis_ getis_ord_gi_star_spatial_statistics_.htm

Feiock, R. C. (2007). Rational choice and regional governance. Journal of Urban Affairs, 29, 47-63.

Feiock, R. C. (2008). Institutional collective action and local government collaboration. In L. B. Bingham \& R. O'Leary (Eds.), Big ideas in collaborative public management (pp. 195-210). Armonk, NY: M. E. Sharpe.

Frederickson, H. G. (1999). The repositioning of American public administration. PS: Political Science and Politics, $32,701-711$.

Freedman, J. (2008). Antisemitism without Jews: Left behind in the heartland. In P. Lassner \& L. Trubowitz (Eds.), Antisemitism and philosemitism in the twentieth and twenty-first centuries (pp. 154-174). Cranbury, NJ: Associated University Presses.

Gainsborough, J. (2002). Slow growth and urban sprawl: Support for a new regional agenda. Urban Affairs Review, 37, 728-744. 
Gerber, E. R. (2005). Regional governance in Michigan. CLOSUP/Ann Arbor Area Chamber of Commerce Policy Report. Ann Arbor: University of Michigan. Available at http://www.umich.edu/CLOSUP

Gerber, E.R., \& C.G. Loh. (2011). Prospects for expanding regional planning efforts in Michigan. Urban Studies, 48, 2303-2319.

Getis, A., \& Ord, J. K. (1992). The analysis of spatial association by use of distance statistics. Geographical Analysis, 24, 189-206.

Howell-Moroney, M. (2008). The Tiebout hypothesis 50 years later: Lessons and lingering challenges for metropolitan governance in the 21st century. Public Administration Review, 68, 97-109.

Jacobs, A. J. (2003). Embedded autonomy and uneven metropolitan development: A comparison of the Detroit and Nagoya auto regions, 1969-2000. Urban Studies, 40, 335-360.

Jacobs, J. (1961). The death and life of great American cities. New York: Random House.

Katz, B. (2000). Editor's overview. In B. Katz (Ed.), Reflections on regionalism (pp. 1-8). Washington, DC: Brookings Institution Press.

Kern, K., \& Alber, G. (2009, October). Governing climate change in cities: Modes of urban climate governance in multi-level systems. Paper presented at the International Conference on Competitive Cities and Climate Change, Milan, Italy.

Leroux, K., \& Carr, J. B. (2007). Explaining local government cooperation on public works. Public Works Management and Policy, 12, 344-358.

May, P. J. (1995). Can cooperation be mandated? Implementing intergovernmental environmental management in New South Wales and New Zealand. Publius: The Journal of Federalism, 25(1), 89-113.

McGee, M. P., \& Trebilcock, C. M. (2007). Intergovernmental cooperation in Michigan: A policy dialogue, white paper B: Legal barriers to intergovernmental cooperation, "Legal Issues" (Urban Cooperation Act). Retrieved from www.landpolicy.msu.edu

Mohamed, R. (2008). Who would pay for rural open space preservation and inner-city redevelopment? Identifying support for policies that can contribute to regional land use governance. Urban Studies, 45, 2783-2803.

Norris, D. F. (2001). Whither metropolitan governance? Urban Affairs Review, 36, 532-550.

Olberding, J. C. (2002). Does regionalism beget regionalism? The relationship between norms and regional partnerships for economic development. Public Administration Review, 62, 480-491.

Post, S. S. (2002). Local government cooperation: The relationships between metropolitan area government geography and service provision. Annual Meetings of the American Political Science Association. Boston, MA. Retrieved May 31, 2012, from http://localgov.fsu.edu/papers/archive/PostStephanie.pdf

Post, S. S. (2004). Metropolitan area governance and institutional collective action. In R. C. Feiock (Ed.), Metropolitan governance: Conflict, competition, and collaboration (pp. 67-92). Washington, DC: Georgetown University Press.

Powell, J. A. (2000). Addressing regional dilemmas for minority communities. In B. Katz (Ed.), Reflections on regionalism (pp. 218-246). Washington, DC: Brookings Institution Press.

Rusk, D. (2000). Growth management: The core regional issue. In B. Katz (Ed.), Reflections on regionalism (pp. 78-106). Washington, DC: Brookings Institution Press.

Savitch, H. V., \& Vogel, R. K. (2000). Introduction: Paths to new regionalism. State and Local Government Review, $32,158-168$.

Schneider, K. (2003). Michigan apartheid: Reforming land use policy can help most segregated state. Retrieved May 21,2013, from http://www.mlui.org/mlui/news-views/articles-from-1995-to-2012.html?archive_id = 204.UZ0Gj-shMrg

Snyder, R. (2011). A special message from Governor Rick Snyder: Community development and local government reforms. Retrieved from www.michigan.gov

Thurmaier, K. (2006). High-intensity interlocal collaboration in three Iowa cities. Public Administration Review, 66, $144-146$.

Visser, J. A. (2002). Understanding local government cooperation in urban regions: Toward a cultural model of interlocal Relations. American Review of Public Administration, 32(1), 40-65.

Visser, J. A. (2004). Voluntary regional councils and the new regionalism: Effective governance in the smaller metropolis. Journal of Planning Education and Research, 24, 51-63.

Wheeler, S. M. (2002). The new regionalism: Key characteristics of an emerging movement. Journal of the American Planning Association, 68, 267-278.

Williams, O. P. (1967). Life style values and political decentralization in metropolitan areas. Southwestern Social Science Quarterly, 48(3), 299-310.

Zeemering, E. S. (2009). California county administrators as sellers and brokers of interlocal cooperation. State and Local Government Review, 41(3), 166-181. 


\section{ABOUT THE AUTHORS}

Elisabeth R. Gerber is the Jack L. Walker, Jr. Professor of Public Policy in the Gerald R. Ford School of Public Policy, Professor of Political Science (by courtesy), and Research Associate at the Center for Political Studies, Institute for Social Research, University of Michigan. Her current research focuses on regionalism and intergovernmental cooperation, urban climate adaptation, transportation policy, state and local economic policy, land use and economic development, local fiscal capacity, and local political accountability. She received her $\mathrm{PhD}$ in political science from the University of Michigan.

Carolyn G. Loh is an Assistant Professor in the Department of Urban Studies and Planning at Wayne State University. Her research interests include land use, GIS, implementation, intergovernmental cooperation, and regional planning. She received her $\mathrm{PhD}$ in urban and regional planning from the University of Michigan. 